INCOTW - Sassari, Italy (2017)

"International Congress on Cork Oak Trees and Woodlands"

Guest Editors: Piermaria Corona, Sandro Dettori

\title{
Molecular evidence of bidirectional introgression between Quercus suber and Quercus ilex
}

\author{
Unai López De Heredia, \\ Héctor Sánchez, \\ Álvaro Soto
}

\section{Introduction}

Hybridization between cork oak (Quercus suber L.) and holm oak (Q. ilex L.) has been known for a long time. The first written references to putative hybrid individuals date back to the mid-19 ${ }^{\text {th }}$ century (Colmeiro $\&$

GI Genética, Fisiología e Historia Forestal, Dpto. Sistemas y Recursos Naturales, ETSI Montes, Forestal y del Medio Natural, Universidad Politécnica de Madrid, Madrid (Spain)

\section{@ Álvaro Soto (asdv00@gmail.com)}

Received: Jul 28, 2017 - Accepted: Feb 20, 2018

Citation: López De Heredia U, Sánchez H, Soto Á (2018). Molecular evidence of bidirectional introgression between Quercus suber and Quercus ilex. iForest 11: 338-343. doi: 10.3832/ifor2570-011 [online 2018-0418]

Communicated by: Piermaria Corona

Cork oak and holm oak share a large part of their natural range, and are known to hybridize in mixed stands. This hybridization is supposed to have played a relevant role in the past history of cork oak. Previous research has reported that $F_{1}$ hybrids are produced with holm oak acting as pollen recipient, therefore carrying holm oak chloroplast. Additionally, $F_{1}$ hybrids have been assumed to be pollinated mostly by cork oak. Continued backcrossing of $F_{1}$ hybrids with cork oak (supported by flowering phenology) could have created the organellar introgression patterns observed nowadays in Eastern Spain and Southern France cork oak populations. On the contrary, no organellar introgression has been detected in holm oak and multiple generation backcross individuals to holm oak have not been reported so far. In this work, we examined whether hybrids preferentially backcross with cork oak or with holm oak. To reach this goal, we genotyped by using eight microsatellite loci the progeny of four cork and four holm oak trees (33 and 44 half-siblings, respectively), and of four hybrids (468 half-siblings) collected over three years from a natural mixed population. We used the STRUCTURE software to estimate the proportion of the genotype of each seedling inherited from cork oak $\left(q_{s}\right)$ or from holm oak $\left(q_{i}\right)$. The ratio of the offspring $q$ value over the mother $q$ value helped determine the source of pollen that originated each acorn. Our results show for the first time that hybrid trees can be effectively pollinated by both parental species. Additionally, each hybrid tree was predominantly pollinated by the most abundant oak species in its vicinity. These results confirm the occurrence of bidirectional introgression, previously suggested for adult hybrid trees in the field, and point out the pattern of introgression in the seedlings could be most affected by the abundance of the parental species.

Keywords: Cork Oak, Holm Oak, Hybridization, Introgression, Microsatellites

Boutelou 1854, Laguna 1881, Borzi 1881). The ranges of cork and holm oak overlap in the western Mediterranean basin, where they form mixed stands on acid and decarbonated soils, the preferred ones for cork oak. Morphologically intermediate, presumably hybrid individuals, can be found in these stands, and are easily identifiable by their bark, and by some leaf intermediate traits, such as leaf thickness, which show characteristics of both parental species (Laguna 1881). These putative hybrid individuals occur at low frequency and are scattered among the pure cork and holm oaks. Introgression of genes from one species to another can have important adaptive and evolutionary consequences (Excoffier et al. 2009, Petit et al. 2004). In the case of holm and cork oaks, it has been proposed that such process may have helped cork oak thrive in adverse environmental conditions (e.g., during the glacial pulses of the Pleistocene - López de Heredia et al. 2007).

Molecular markers have confirmed the hybrid nature of phenotypically intermediate individuals and were used to assess the extent of hybridization between Q. suber and $Q$. ilex in natural mixed populations. Analysis of chloroplast DNA (cpDNA), which is maternally inherited in oaks, detected $Q$. suber populations in Southern France and Eastern Spain with a typical Q. ilex lineage cpDNA (Jiménez et al. 2004, López de Heredia et al. 2005, Lumaret et al. 2005). Phenology of both species as well as post pollination barriers as those reported by Boavida et al. (2001) favor hybridization with $Q$. suber acting as pollen donor, so that hybrids carry the ilex chloroplast. Chloroplast introgression pattern suggests hybrid trees carrying the ilex chloroplast recurrently backcrossed with $Q$. suber as pollen donor. Using isozymes (Elena-Rosselló et al. 1992, Oliveira et al. 2003) or nuclear microsatellites (Soto et al. 2003, Burgarella et al. 2009), previous studies confirmed the hybrid character of morphologically intermediate oak trees, and showed the current existence of hybridization. Burgarella et al. (2009) estimated a low rate of ongoing introgression in cork oak over its range ( $2 \%)$, a result confirmed by Lumaret \& Jabbour-Zahab (2009- 4\%). These stud- 
ies suggested that introgression could occur bidirectionally. However, if the flowering phenology of first generation hybrids ( $F_{1}$ hybrids) is more similar to $Q$. suber, as suggested by Perea García-Calvo (2006), they would preferentially backcross with Q. suber, while mating with Q. ilex, especially when the latter species acts as pollen donor, would be much less frequent.

In the current work, we genotyped seedlings of morphologically putative hybrid trees, to identify backcrossing events with either Q. ilex or Q. suber as pollen donors, and to quantify the frequency of introgression towards each of the parental species. Our study provides a deeper insight in the hybridization and introgression processes which could be currently taking place between these two species.

\section{Material and methods}

\section{Sampling site and acorn collection}

The sampling site is located in Central Spain, $\left(39^{\circ} 59^{\prime} \mathrm{N}, 05^{\circ} 07^{\prime} \mathrm{W}\right)$ in a mixed "dehesa", i.e., highly anthropized open woodland. Quercus suber and Q. ilex are the dominant species, while there are some stands with comparatively few Q. faginea individuals. Four mature hybrid trees were identified by their phenotypes. These hybrid trees occurred in three distinct areas (IS, LG, and ZL) which differed in tree density and species composition. One hybrid was identified in IS, where Q. ilex and Q. suber occur at a density of 38 trees ha ${ }^{-1}$ and where Q. suber is slightly more abundant. Two hybrids were found in LG, approximately $25 \mathrm{~m}$ apart and $740 \mathrm{~m}$ away from the IS hybrid. At LG, tree density was low (20 trees $h^{-1}$ ) and dominated by Q. ilex. The fourth hybrid tree was found in $\mathrm{ZL}$, where tree density was 123.5 trees/ha, with more Q. suber trees ( 38.3 trees ha-1 for Q. ilex and 85.2 trees ha ${ }^{-1}$ for Q. suber), and approximately $2780 \mathrm{~m}$ away from the two LG hybrids and $3140 \mathrm{~m}$ away from the IS hybrid.

Acorns were collected in 2011, 2012 and
2014 on each of the four hybrids trees and also from four randomly selected cork oak and four holm oak trees located in IS (Tab. 1). Each year, all acorns from $L G 2$ and $Z L$ hybrid trees were collected, as well as approximately $1 / 3$ of the acorns on the LG1 and IS hybrids.

All collected acorns were sown in peatperlite substrate (3:1 proportion) in $3 \mathrm{~L} \mathrm{con-}$ tainers in a greenhouse room kept at $22^{\circ} \mathrm{C}$, with a relative humidity of $50-60 \%$. Seedlings were watered daily for $8 \mathrm{~min}$. and five months after sowing, germination rate was estimated and leaf tissue collected from the surviving seedlings for DNA extraction.

\section{Genotyping}

DNA extraction was performed with a modification of the protocol by Doyle \& Doyle (1990 - Dumolin et al. 1995). We used eight polymorphic nuclear microsatellites (nSSRs) for genotyping: MSQ4, MSQ13 (Dow et al. 1995), QpZAG9, QpZAG15, QpZAG36, (Steinkellner et al. 1997), QrZAG7, QrZAG11 and QrZAG20 (Kampfer et al. 1998). Microsatellites were amplified under standard PCR conditions (Soto et al. 2003, 2007). Fluorescence labelled PCR products were analyzed in a $4300 \mathrm{LI}^{-\mathrm{COR}^{\circledast}}$ automated sequencer (LI-COR Biosciences, Lincoln, NE, USA). Allele sizes were determined with the SAGA Microsatellite Analysis Software (LI-COR Biosciences, Lincoln, NE, USA). The presence of null alleles was examined using ML-Null (Kalinowski \& Taper 2006).

\section{Nuclear admixture analyses}

We carried out admixture analyses using the Bayesian clustering approach implemented in the program STRUCTURE ver. 2.3.4 (Pritchard et al. 2000). In this model, the posterior probability $(q)$ provides an estimation of the proportion of an individual genome originating from each of $K$ differentiated genetic pools. Values of $K$ ranging from 1 to 5 were tested in order to find the optimal $K$ value. A value of $K=2$ was identified as the optimal $K$ value following the

Tab. 1 - Number of acorns sewed, germinated, and genotyped (sewed-germinatedgenotyped) categorized by mother tree (family), taxa and cohort.

\begin{tabular}{lllll}
\hline Taxa & Genotype & $\mathbf{2 0 1 1}$ & $\mathbf{2 0 1 2}$ & $\mathbf{2 0 1 4}$ \\
\hline Hybrids & LG1 & $184-155-148$ & $36-24-21$ & $59-39-38$ \\
& LG2 & $19-3-3$ & - & $14-5-5$ \\
& IS & $106-85-84$ & $76-61-59$ & $95-77-77$ \\
& ZL & $12-0-0$ & $36-24-19$ & $34-14-14$ \\
\cline { 2 - 4 } Q. ilex & Total & $321-243-235$ & $148-109-99$ & $202-135-134$ \\
& I1 & - & $22-21-19$ & $5-5-5$ \\
& I2 & - & $12-11-9$ & $5-4-4$ \\
& I3 & - & - & $4-4-4$ \\
& I4 & - & - & $5-3-3$ \\
& Total & - & $34-32-28$ & $19-16-16$ \\
& S1 & - & $12-8-8$ & $4-2-2$ \\
& S2 & - & $18-12-11$ & $5-4-4$ \\
& S3 & - & - & $5-4-4$ \\
& S4 & - & - & $5-4-4$ \\
& Total & - & $30-20-19$ & $19-14-14$ \\
\hline
\end{tabular}

methodology described by Evanno et al. (2005) and was used in all subsequent analyses. In order to improve $q$ estimations (Burgarella et al. 2009), we included in the STRUCTURE analyses the genotypes of approximately 95 Q. ilex and 96 Q. suber parental trees from the same stand, previously analyzed by Soto et al. (2007), along with 59,671 virtual individuals simulated with the software SimHyb (Soto et al. 2018). These simulated individuals included a majority of parental trees with some $F_{1}$ hybrids and backcrosses (Tab. S1 in Supplementary material).

Calculations were carried out under the admixture model assuming independent allele frequencies, as it has been done previously (Burgarella et al. 2009). A burn-in of 50,000 steps followed by 100,000 iterations were used, after verifying that results did not vary significantly across runs or with longer burn-in/iteration cycles. Assignation of seedlings to specific categories based on the $q_{\mathrm{s}}$ values (estimation of the proportion of the genome coming from $Q$. suber) used the following thresholds: $q_{\mathrm{s}} \geq$ 0.85 : suber; $0.85<q_{s} \leq 0.65$ : suberoid; 0.65 $\leq q_{\mathrm{s}}<0.35$ : hybrid; $0.35 \leq q_{\mathrm{s}}<0.15$ : ilicioid; $q_{\mathrm{s}} \leq 0.15$ : ilex. The software Colony (Jones \& Wang 2010) was used to infer selfing rates in the progeny using the adult trees as potential fathers and allowing up to one mismatch per seedling, and to detect potential crosses between hybrid trees.

The software R ( $R$ Core Team 2013) was used to draw graphics, linear regressions between putative paternal $q_{\mathrm{s}}$ and $q_{\mathrm{so}} / q_{\mathrm{sm}}$ (the ratio between the offspring and the maternal $q_{\mathrm{s}}$ ), and to prepare a script to obtain all the possible paternal contributions for each offspring.

\section{Results and discussion}

\section{Germination rates}

A total of 671 acorns were collected from hybrid trees, and 53 and 49 acorns from Q. ilex and Q. suber, respectively (Tab. 1). Hybrid trees from $L G_{2}$ and $Z L$ produced fewer acorns than hybrid trees from LG1 and IS, and their germination rates were also lower ( $24 \%$ and $46 \%$, respectively), while germination rates were above $70 \%$ for hybrids from LG1 and IS, as well as for the parental species trees (Fig. S1 in Supplementary material).

\section{Assignation to specific categories}

We did not detect null alleles for any locus. Autofecundation was ruled out, as the estimated selfing probability was $<0.001$ for every hybrid seedling. Moreover, mating between hybrid trees was also discarded after inspection of potential parents for each offspring estimated by Colony. The most probable number of differentiated genetic pools in the population was $K=2$ (Fig. S2). The $q_{s}$ values (estimation of the proportion of the genome coming from Q. suber) obtained for the hybrid trees were 0.8763 for IS, 0.5988 for LG1, 
Fig. 1 - Boxplots of the $q_{\mathrm{s}}$ parameter across families for (a) all years combined and separately for (b) 2011, (c) 2012 , and (d) 2014. Sample sizes are presented in Tab. 1.

(a)

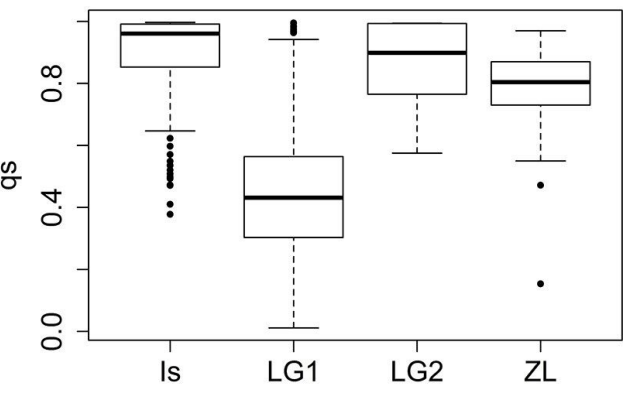

(c)

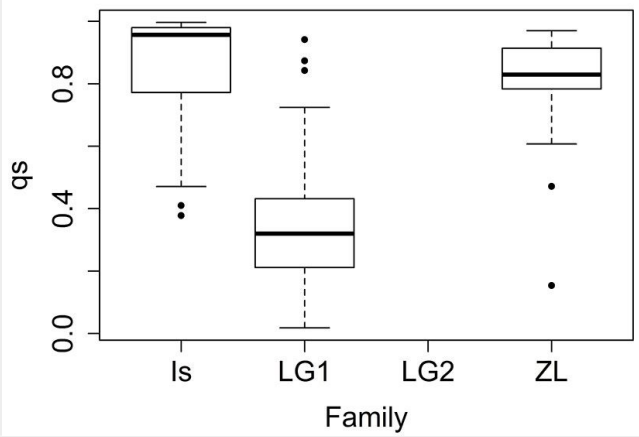

(b)

2011

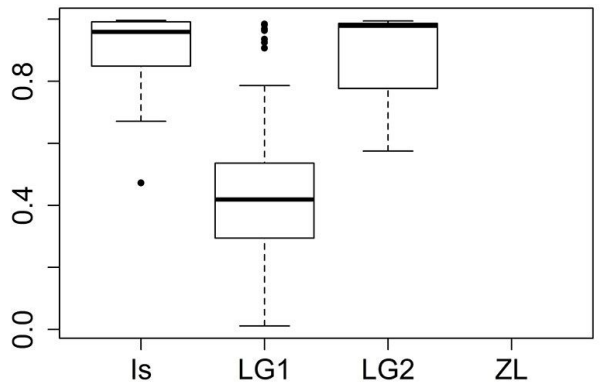

(d)

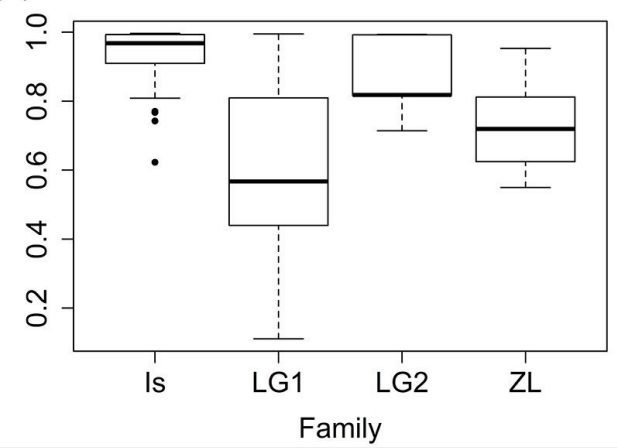

0.8680 for LG2 and 0.5489 for ZL. These re- the progenies of the hybrids (Fig. 1). The sults would classify the hybrid trees at LG1 high $q_{\mathrm{s}}$ values obtained for most of the hyand $\mathrm{ZL}$ as most likely first generation hy- brid offspring, particularly for IS, LG2 and brids $\left(F_{1}\right)$, and hybrid trees at IS and LG2 as ZL, indicate a high contribution of Q. suber more "advanced introgressed" individuals, to their genomes and therefore previous at least second-generation backcrosses works could have classified these seedlings with $Q$. suber. These results are consistent with preferential backcrossing with $Q$. suber.

Then, $q_{\mathrm{s}}$ values were also estimated for as backcrosses to Q. suber. Conversely, the offspring of LG1 shows a broader range of $q_{\mathrm{s}}$, with an average value of 0.4512 , closer to Q. ilex. However, assignation to specific classes based exclusively on $q_{\mathrm{s}}$ may be biased using this set of markers, especially for advanced introgressed individuals (Soto et al. 2018). Actually, more than $30 \%$ of the virtual introgressed individuals included in the simulation as control would be misassigned according to $q_{\mathrm{s}}$. Following Soto et al. (2018), we used the ratio $q_{\mathrm{so}} / q_{\mathrm{sm}}$ to determine the most likely genetic pool of the pollen donor for each offspring (Fig.

Fig. 2 - Histograms of the relative frequencies of the $q_{\mathrm{so}} / q_{\mathrm{sm}}$ ratio between the offspring and the maternal $q_{\mathrm{s}}$ for Is (a), LG1 (b), LG2 (c), and ZL (d) families. The bars to the right of the vertical red line indicate pollination by individuals with a higher percentage of suber genomes. The bars to the left of the vertical red line indicate pollination by individuals with a higher percentage of ilex genomes.

(c)
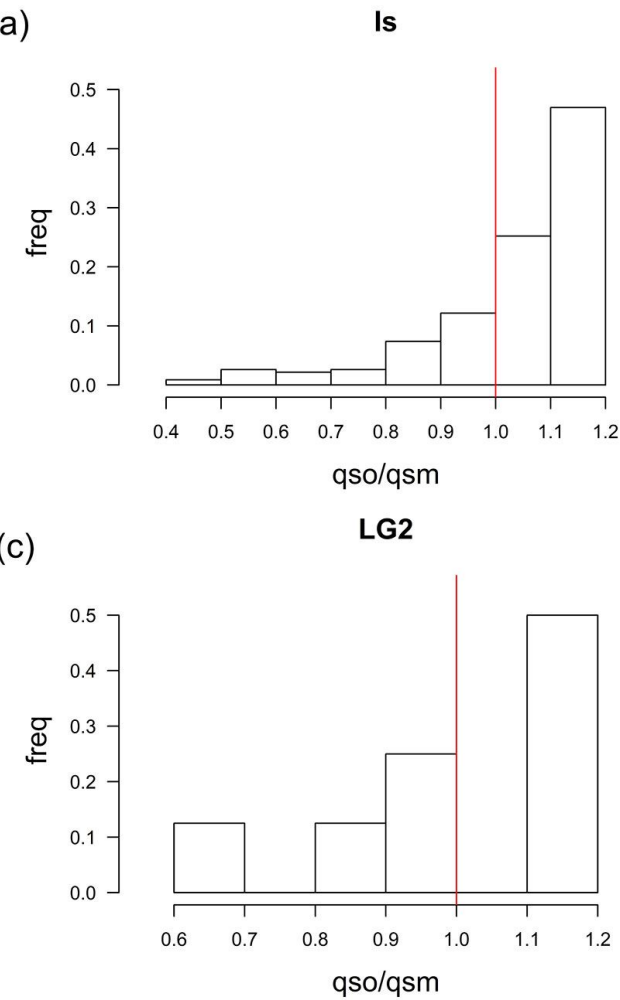

(b)

LG1

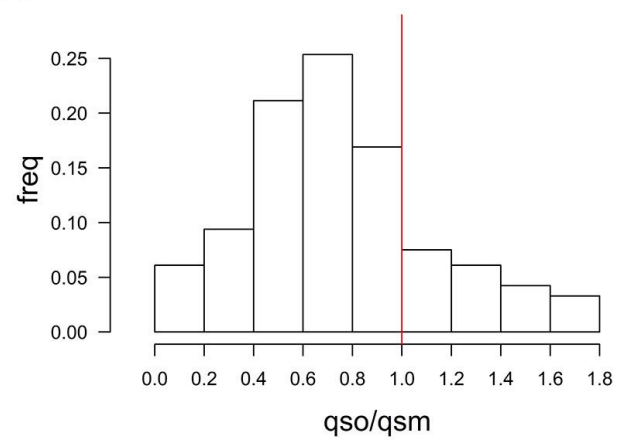

(d)

ZL

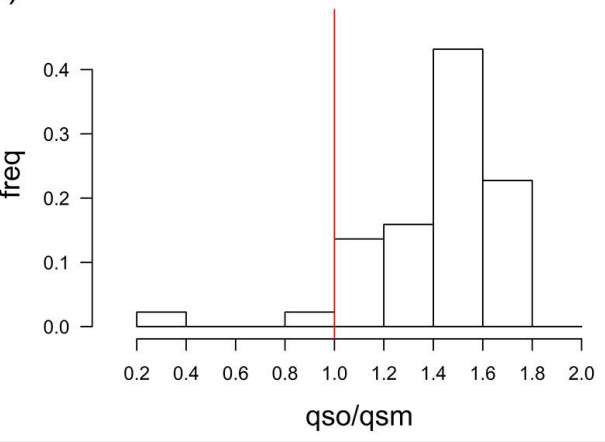


(a)

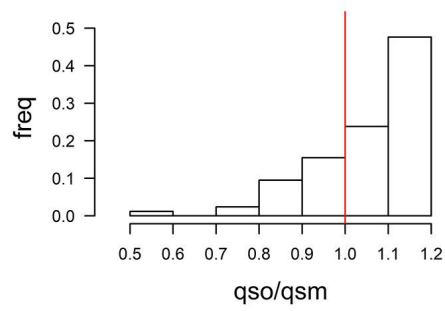

(d)

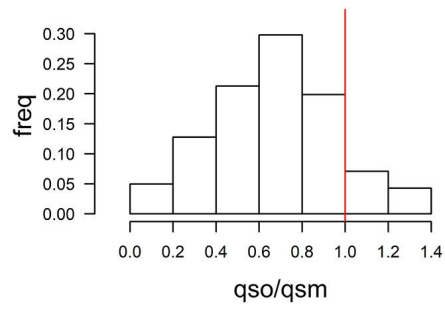

(b)

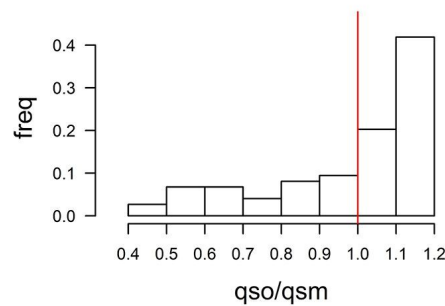

(e)

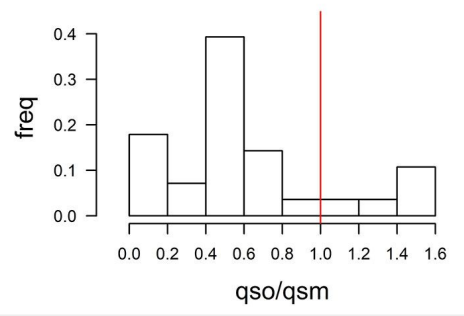

(c)

Is - 2014

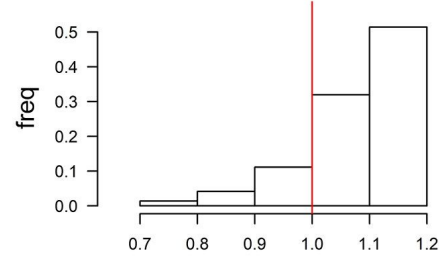

qso/qsm

(f)

LG1 - 2014

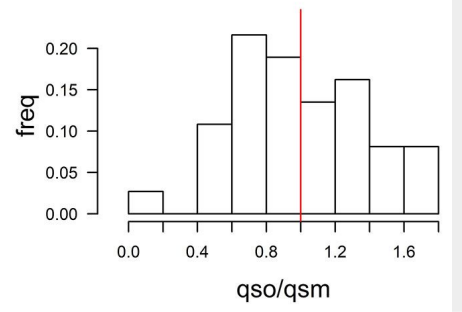

Fig. 3 - Histograms for the relative frequencies of the ratio between the offspring and the maternal $q_{\mathrm{s}}$ for the families Is in 2011 (a), 2012 (b), 2014 (c), and LG1 in 2011 (d), 2012 (e), and 2014 (f). The bars to the right of the vertical red line indicate pollination by individuals with a higher percentage of suber genomes. The bars to the left of the vertical red line indicate pollination by individuals with a higher percentage of ilex genomes.
2). These data support backcrossing with both parental species with many of the LG1 offspring having Q. ilex as father, and many offspring of the IS and ZL hybrid trees having $Q$. suber as father. Offspring of the LG2 hybrid tree had either Q. suber or Q. ilex as father. Fig. 3 shows the distribution of the $q_{\mathrm{s}}$ ratio throughout the studied years for IS and $\mathrm{LG} 1$, the trees that produced more acorns. Although the general trends are kept for the whole period, some differences among years can be noticed, particularly for LG1: in 2011, probably a masting year with high acorn production, the vast majority of the seedlings came from Q. ilex pollen (84.5\%), while in 2014 , with a much lower acorn production, the proportion of effective pollinations from Q. ilex decreased to $54.1 \%$.

To get additional support for the results on pollination direction we prepared an $R$ script to compare each individual offspring and its mother's genotypes, and to obtain all the possible paternal genetic contributions (haplotypes). We then estimated their $q_{s}$ value using STRUCTURE. Fig. $4 a$ shows a boxplot of the distribution of the $q_{\mathrm{s}}$ values assigned to all the possible paternal haplotypes for each mother tree, and Fig. $4 \mathrm{~b}$ and Fig. $4 \mathrm{c}$ show these distribution
Fig. 4 - Boxplots of the $q_{\mathrm{s}}$ parameter of the

inferred putative fathers across families (a), and across cohorts for Is (b) and LG1 (c) families.

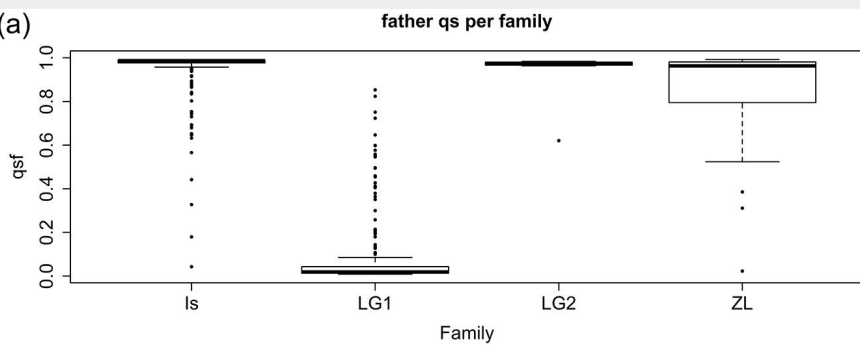

(b)

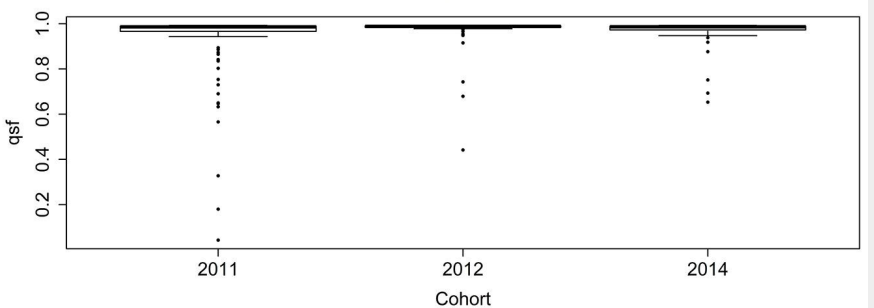

(c)

father qs per cohort. LG1

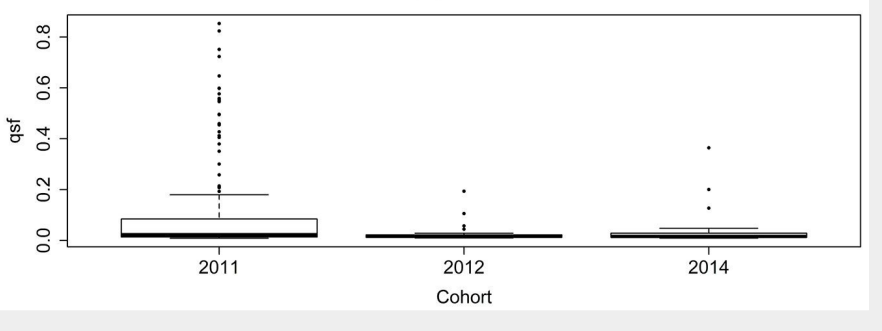

through the studied years for IS and LG1.

Finally, Fig. 5 shows the significant correlations above 0.80 for the estimated paternal $q_{\mathrm{s}}$ and the ratio $q_{\mathrm{so}} / q_{\mathrm{sm}}$, especially for IS (Fig. 5a) and LG1 (Fig. 5b), the trees with larger progenies. This result confirms that using the ratio $q_{\mathrm{so}} / q_{\mathrm{sm}}$ is a good approach to identify the genetic pool of the pollen donor, provided the mother tree is known.

These results support bidirectional introgression, where hybrid trees backcross with both parental species. Bidirectional introgression was also suggested by genotypic data collected by Burgarella et al. (2009) using the same set of nuclear microsatellite markers, on adult trees phenotypically classified as Q. suber and as Q. ilex sampled all across the overlapping distribution ranges of these two species. Lumaret \& Jabbour-Zahab (2009), using the same set of microsatellite markers, also reported the possibility of bidirectional introgression.

Each adult hybrid receives pollen from both parental species but is preferentially pollinated by either Q. ilex or Q. suber (Fig. 2). The major pollen donor for each hybrid tree seems to reflect the abundance of parental tree species in the area. For example, the hybrid tree LG1, located in La Laguna, is mostly pollinated by Q. ilex, the dominant species in that area (the number of seedlings from LG2 is too low to be conclusive); on the other hand, IS and ZL hybrids produced more seedlings from $Q$. suber pollen, the more abundant species in these areas. Therefore, the frequency of backcrossing with a parental species could be at least partially driven by pollen availability. Simulation studies using the oak complex $Q$. robur $\times Q$. petraea have shown that the direction of introgression can be influenced by the composition of the pollen pool on individuals or stigmas which is itself affected by the spatial configuration of the parental species (Lagache et al. 2013, Klein et al. 2017). The direction of introgres- 
Fig. 5 - Correlation of the ratio between the offspring and the maternal $q_{\mathrm{s}}$ and the $q_{\mathrm{s}}$ parameter of the inferred putative fathers for Is (a), LG1 (b), LG2 (c), and ZL (d) families. Fitted linear model for each family are indicated.
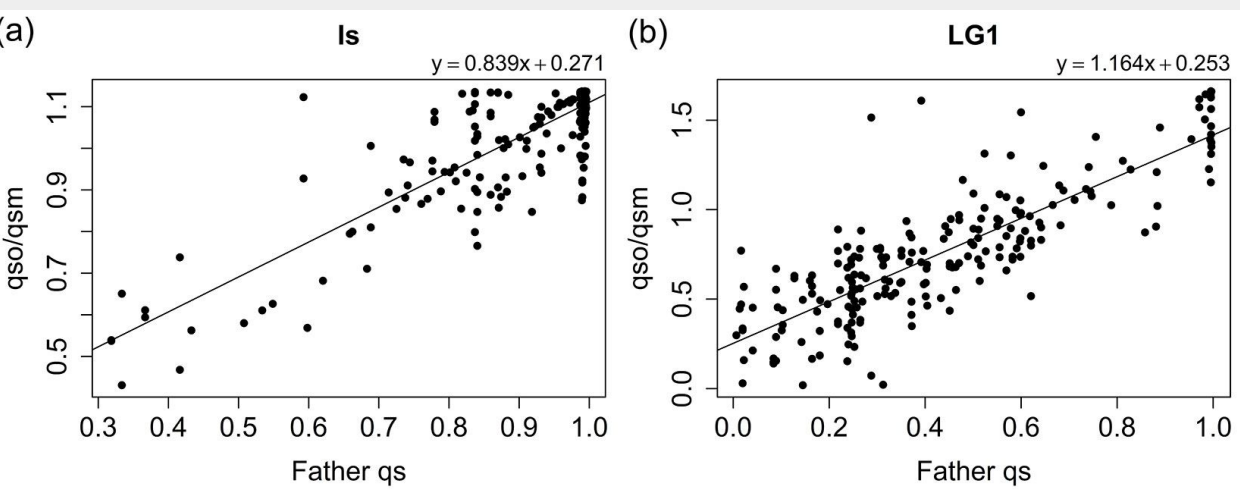

(c)

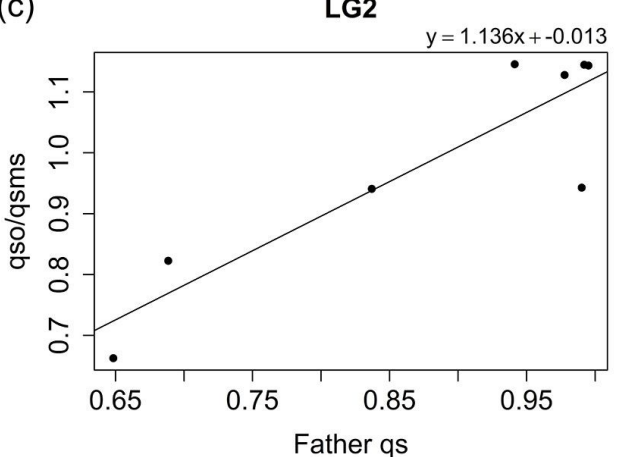

sion depending on the abundance of the parental species in an area would be consistent with the findings in Eucalyptus (Field et al. 2008), Senecio (Prentis et al. 2007) and some mangroves (Zhou et al. 2008).

Based on differential growth rate of pollen tubes, Boavida et al. (2001) reported significantly higher success rate for the interspecific crosses with Q. suber acting as pollen donor rather than as female parent. However, the high number of hybrid offspring having Q. ilex as pollen donor, supports at least the partial breakage of this prezygotic incompatibility between introgressed hybrids and Q. ilex pollen. Notwithstanding, a potential effect of post-zygotic barriers on the observed gene flow directionality cannot be discarded. If some type of incompatibility existed between the two parental species, a high proportion of viable embryos could be expected for families of parent trees that have similar specific categories (estimated in our case through $q_{s}$ ). Interestingly, the majority of seedlings of the IS parent, classified as an "advanced introgressed" cork oak tree $\left(q_{\mathrm{s}}\right.$ $=0.8763$ ), had Q. suber as pollen donor. However, although both ZL and LG1 hybrids show intermediate $q_{\mathrm{s}}$ values $(0.5489$ and 0.5988 , respectively), they show contrasting proportions of effective pollinations from Q. suber and Q. ilex. As previously stated, the $Q$. ilex neighborhood of LG1 could account for the abundance of $L G 1 \times Q$. ilex backcrosses. In the case of ZL an overabundance of backcrosses to $Q$. suber was scored, considering the specific composition of the surrounding trees. Although the number of seedlings from this tree is still low to draw definitive conclu- sions, this fact could be due to a phenological synchrony between this tree's female flowers and pollination of the surrounding Q. suber (Perea García-Calvo 2006), or to post-pollination processes (Varela et al. 2008), such as genomic incompatibilities between this hybrid and surrounding Q. ilex individuals. As shown for European white oaks, first-generation hybrids will also more likely mate with the more abundant species, leading to potential asymmetric introgression (Lepais et al. 2009). Asymmetric introgression based on the abundance of the parental species has been described in other Mediterranean (Neophytou et al. 2011) and non-Mediterranean tree species (Bacilieri et al. 1996, Curtu et al. 2007, Eaton et al. 2015).

\section{Conclusions}

These results support current bidirectional introgression with Q. suber and Q. ilex. Analysis of the progenies of four open pollinated hybrid trees from a natural mixed population reveals that each mother tree is predominantly fertilized by one of the two parental species, usually the most abundant in its vicinity. The frequency of backcrossing could at least be partially driven by the availability of pollen when female flowers are receptive. However, other post-pollination processes, such as genetic incompatibilities cannot be excluded. To clarify this point, controlled pollinations and monitoring of pollen tube development and abortion of embryos should be performed. Additionally, further investigations should take advantage of modern high-throughput sequencing methodologies that will allow the examination of larger proportions of the species' genomes. Moreover, using these methodologies, it may be possible to identify the genome portions that determine hybridizing capability, and/or reproductive isolation in the Q. ilex - Q. suber complex.

\section{Acknowledgements}

AS and ULH conceived the idea, designed the experiments, collected the plant material and drafted the manuscript; HS and ULH genotyped the seedlings and adult trees; ULH, HS and AS performed the admixture and statistical analyses. All the authors have contributed to the final manuscript.

This work has been funded by the project AGL2015-67495-C2-2-R (Spanish Ministry of Economy and Competitiveness).

The authors thank the two anonymous reviewers for their helpful comments and suggestions.

\section{References}

Bacilieri R, Ducousso A, Petit RJ, Kremer A (1996). Mating system and asymmetric hybridization in a mixed stand of European oaks. Evolution 50 (2): 900-908. - doi: 10.1111/j.15585646.1996.tbo3898.x

Boavida LC, Silva JP, Feijó LA (2001). Sexual reproduction in the cork oak (Quercus suber L.) II. Crossing intra- and interspecific barriers. Sexual Plant Reproduction 14: 143-152. - doi: 10.1007 /s004970100100

Borzi A (1881). L'llixi-Suergiu (Quercus morisiiborzi), nuova Quercia della Sardegna [The IlixiSuergiu (Quercus morisii-borzi), a new oak of Sardinia]. Nuovo Giornale Botanico Italiano 13 (1): 3-10. [in Italian]

Burgarella C, Lorenzo Z, Jabbour-Zahab R, Lumaret R, Guichoux E, Petit RJ, Soto A, Gil L (2009). Detection of hybrids in nature: applica- 
tion to oaks (Quercus suber and Q. ilex). Heredity 102: 442-452. - doi: 10.1038/hdy.2009.8

Colmeiro M, Boutelou E (1854). Examen de las Encinas y demás arboles de la Peninsula Iberica que producen bellotas, con la designación de los que se llaman mestos [Analysis of holm oaks and other acorn-producing trees in the Iberian Peninsula, with the description of the so-called "mestos"]. D. Jose M. Geofrin Ed., Sevilla, Spain, pp. 16. [in Spanish]

Curtu AL, Gailing O, Finkeldey R (2007). Evidence for hybridization and introgression within a species-rich oak (Quercus spp.) community. BMC Evolutionary Biology 7 (1): 218. - doi: 10.118 6/1471-2148-7-218

Dow B, Ashley M, Howe H (1995). Characterization of highly variable (GA/CT)n microsatellites in the bur oak, Quercus macrocarpa. Theoretical and Applied Genetics 91: 137-141. - doi: 10.1007/ BFo0220870

Doyle J, Doyle J (1990). Isolation of plant DNA from fresh tissue. Focus 13: 13-15.

Dumolin S, Demesure B, Petit RJ (1995). Inheritance of chloroplast and mitochondrial genomes in pedunculate oak investigated with an efficient PCR method. Theoretical and Applied Genetics 91: 1253-1256. - doi: 10.1007/BF002209 37

Eaton DAR, Hipp AL, González-Rodríguez A, Cavender-Bares J (2015). Historical introgression among the American live oaks and the comparative nature of tests for introgression. Evolution 69: 2587-2601. - doi: 10.1111/evo.12758

Elena-Rosselló JA, Lumaret R, Cabrera E, Michaud H (1992). Evidence for hybridization between sympatric holm oak and cork oak in Spain based on diagnostic enzyme markers. In: "Quercus ilex L. Ecosystems: Function, Dynamics and Management" (Romane F., Terradas J eds). Advances in Vegetation Science, vol. 13, Springer, Dordrecht, Netherlands, pp. 115-118. doi: 10.1007/978-94-017-2836-2_11

Evanno G, Regnaut S, Goudet J (2005). Detecting the number of clusters of individuals using the software STRUCTURE: a simulation study. Molecular Ecology 14: 2611-2620. - doi: 10.1111/j. 1365-294X.2005.02553.x

Excoffier L, Hofer T, Foll M (2009). Detecting loci under selection in a hierarchically structured population. Heredity 103: 285-298. - doi: 10.103 8/hdy.2009.74

Field DL, Ayre DJ, Whelan RJ, Young AG (2008). Relative frequency of sympatric species influences rates of interspecific hybridization, seed production and seedling performance in the uncommon Eucalyptus aggregate. Journal of Ecology 96: 1198-1210. - doi: 10.1111/j.1365-2745. 2008.01434.x

Jiménez P, López De Heredia U, Collada C, Lorenzo Z, Gil L (2004). High variability of chloroplast DNA in three Mediterranean evergreen oaks indicates complex evolutionary history. Heredity 93: 510-515. - doi: 10.1038/sj.hdy.68005 51

Jones OR, Wang J (2010). COLONY: a program for parentage and sibship inference from multilocus genotype data. Molecular Ecology Resources 10: 551-555. - doi: 10.1111/j.1755-0998.20 09.02787.x

Kalinowski ST, Taper ML (2006). Maximum likelihood estimation of the frequency of null alleles at microsatellite loci. Conservation Genetics 7: 991-995. - doi: 10.1007/s10592-006-9134-9

Kampfer S, Lexer C, Glössl J, Steinkellner H (1998). Characterization of (GA)n microsatellite loci from Quercus robur. Hereditas 129: 183-186. doi: 10.1111/j.1601-5223.1998.00183.x

Klein EK, Lagache-Navarro L, Petit RJ (2017). Demographic and spatial determinants of hybridization rate. Journal of Ecology 105: 29-38. doi: 10.1111/1365-2745.12674

Lagache L, Klein EK, Guichoux E, Petit RJ (2013). Fine-scale environmental control of hybridization in oaks. Molecular Ecology 22: 423-436. doi: 10.1111/mec.12121

Laguna M (1881). Un mesto italiano y varios mestos espanoles [An Italian and several Spanish “mestos"]. Revista Montes 114: 477-486. [in Spanish]

Lepais O, Petit RJ, Guichoux E, Lavabre JE, Alberto F, Kremer A, Gerber S (2009). Species relative abundance and direction of introgression in oaks. Molecular Ecology 18: 2228-2242. - doi: 10.1111/j.1365-294X.2009.04137.x

López de Heredia $U$, Jiménez P, Díaz-Fernández $P$, Gil L (2005). The Balearic Islands: a reservoir of cpDNA genetic variation for evergreen oaks. Journal of Biogeography 32: 939-949. - doi: 10.1111/j.1365-2699.2004.01232.x

López de Heredia U, Carrion JS, Jimenez P, Collada C, Gil L (2007). Molecular and palaeoecological evidence for multiple glacial refugia for evergreen oaks on the Iberian Peninsula. Journal of Biogeography 34 (9): 1505-1517. - doi: 10.1111/j.1365-2699.2007.01715.x

Lumaret R, Tryphon-Dionnet M, Michaud H, Sanuy A, Ipotesi E, Born C, Mir C (2005). Phylogeographical variation of chloroplast DNA in cork oak (Quercus suber). Annals of Botany 96: 853-861. - doi: 10.1093/aob/mci237

Lumaret R, Jabbour-Zahab R (2009). Ancient and current gene flow between two distantly related Mediterranean oak species, Quercus suber and Quercus ilex. Annals of Botany 104: 725736. - doi: 10.1093/aob/mcp149

Neophytou C, Aravanopoulos FA, Fink S, Aravanopoulos $F$ (2011). Interfertile oaks in an island environment. II. Limited hybridization between Quercus alnifolia Poech and Q. coccifera L. in a mixed stand. European Journal of Forest Research 130: 623-635. - doi: 10.1007/s10342-0100454-4

Oliveira P, Custódio AC, Branco C, Reforço I, Rodrigues F, Varela MC, Meierrose C (2003). Hybrids between cork oak and holm oak: isozyme analysis. Forest Genetics 10: 283-297. [online] URL: http://hdl.handle.net/10174/862

Perea García-Calvo R (2006). Estudio de la estructura de masa de una dehesa de encina con alcornoque en "El Deheson del Encinar" (Toledo) [Study of the stand structure of a cork oak and holm oak open woodland in "El Dehesón del Encinar" (Toledo)]. Master Thesis, Universidad Politécnica de Madrid, Madrid, Spain, pp. 78. [in Spanish]

Petit RJ, Bodenes C, Ducousso A, Roussel G, Kremer A (2004). Hybridization as a mechanism of invasion in oaks. New Phytologist 161: 151-164. doi: 10.1046/j.1469-8137.2003.00944.x

Prentis PJ, White EM, Radford IJ, Lowe AJ, Clarke AR (2007). Can hybridization cause local extinction: a case for demographic swamping of the Australian native Senecio pinnatifolius by the invasive Senecio madagascariensis? New Phytologist 176: 902-912. - doi: 10.1111/j.1469-81 37.2007.02217.x

Pritchard JK, Stephens M, Donnely P (2000). Inference of population structure using multilocus genotype data. Genetics 155: 945-959. [online] URL: http://www.genetics.org/conten t/155/2/945

R Core Team (2013). R: a language and environment for statistical computing. R Foundation for Statistical Computing, Vienna, Austria. [online] URL: http://www.R-project.org/

Soto A, Lorenzo Z, Gil L (2003). Nuclear microsatellite markers for the identification of Quercus ilex L. and Q. suber L. hybrids. Silvae Genetica 52: 63-66. [online] URL: http://www.re searchgate.net/publication/236219960

Soto A, Lorenzo Z, Gil L (2007). Differences in fine-scale genetic structure and dispersal in Quercus ilex L. and Q. suber L.: consequences for regeneration of Mediterranean open woods. Heredity 99: 601-607. - doi: 10.1038/sj. hdy. 6801007

Soto A, Rodríguez-Martínez D, López de Heredia $U$ (2018). SimHyb: a simulation software for the study of the evolution of hybridizing populations. Application to Quercus ilex and Q. suber suggests hybridization could be underestimated. iForest - Biogeosciences and Forestry 11 (1): 99-103. - doi: 10.3832/ifor2569-011

Steinkellner $\mathrm{H}$, Fluch S, Turetschek E, Lexer C, Streiff R, Kremer A, Burg K, Glössl J (1997). Identification and characterization of (GA/CT)nmicrosatellite loci from Quercus petraea. Plant Molecular Biology 3: 1093-1096. - doi: 10.1023/ A:1005736722794

Varela MC, Bras R, Barros IR, Oliveira P, Meierrose $C$ (2008). Opportunity for hybridization between two oak species in mixed stands as monitored by the timing and intensity of pollen production. Forest Ecology and Management 256: 1546-1551. - doi: 10.1016/j.foreco.2008.06. 049

Zhou R, Gong X, Boufford D, Wu CI, Shi S (2008). Testing a hypothesis of unidirectional hybridization in plants: observations on Sonneratia, Bruguiera and Ligularia. BMC Evolutionary Biology 8 (1): 149. - doi: 10.1186/1471-2148-8-149

\section{Supplementary Material}

Fig. S1 - Germination rates of the progenies of the hybrids, Q. ilex and Q. suber for 2011, 2012 and 2014.

Fig S2 - Most probable number of genetic groups $(K)$ inferred with the test of Evanno et al. (2005).

Fig S3 - Barplots showing the relative contribution of Q. ilex and Q. suber to each offspring as the proporpotion of $q_{i}$ and $q_{s}$. estimated with STRUCTURE.

Tab. S1 - Number of virtual individuals by the specific categories defined according to $q_{\mathrm{s}}$ intervals generated with SIMHYB (Soto et al. 2017).

Link: Lopez_2570@supploo1.pdf 